\title{
Prophylactic Cranial Irradiation in Limited-Disease Small-Cell Lung Cancer - Why, When, How Much?
}

\section{Bohrer F. Wenz}

Sektion Strahlentherapie, Universitätsklinikum Mannheim
Small-cell lung cancer (SCLC) typically shows rapid proliferation and early dissemination. The central nervous system is a frequent site of relapse. About $10 \%$ of patients initially present with brain metastases and the 2-year cumulative risk rises to approximately $80 \%$ [1]. Because of the natural course, systemic chemotherapy is an important tool, but there is an additional role for locoregional radiotherapy i.e. consolidating thoracic radiotherapy and the controversially discussed prophylactic cranial irradiation (PCI). Thoracic radiotherapy yields an improvement in local control and a significant survival benefit for patients with limited disease [2]. In contrast, there are still ongoing discussions about the benefit of PCI and potential side effects, especially neurotoxicity.

\section{Why Should PCI be Given in SCLC?}

Isolated brain metastases occur in about $30-45 \%$ of patients with limited disease. PCI significantly decreases the risk of brain metastases as site of first failure [3, 4]. Arriagada et al. [3] showed that the 2-year isolated brain metastasis rate was $45 \%$ in the control group (no PCI) and $19 \%$ in the treatment group (with PCI). Therefore PCI may actually cure patients whose lung cancer at the primary site has been eradicated by radiochemotherapy, but who have cerebral micrometastases at the time of primary treatment which are not sufficiently treated because of the blood-brain barrier [5]. Hence, in the absence of PCI, the brain would be the sole site of failure limiting survival. Another aspect is the morbidity in patients with cerebral metastases considering quality of life and the psychological situation caused by tumor localization in the brain.

Despite the relatively high rate of brain metastases in patients with SCLC, the indication for PCI remains controversial. A reason may be the unclear benefit concerning overall survival. Some studies $[6,7]$ found that PCI was not associated with a significantly improved survival. This view changed in 1999 with the meta-analysis of Auperin et al. [8]. They analyzed data of 987 patients with SCLC in complete remission who took part in 7 randomized trials that compared 'PCI' with 'no PCI'. The relative risk (RR) of death in the treatment group as compared with the control group was reduced to 0.84 ( $\mathrm{p}=$ 0.01 ), which corresponds to a significant increase in the rate of survival at 3 years (15.3 vs. $20.7 \%)$, i.e. an increase by one third. Other results confirmed the findings that PCI significantly increases the rate of disease-free survival (RR for progression $=0.75)$ and decreases the cumulative incidence of brain metastasis by half $(\mathrm{RR}=0.46)$.

Numerous retrospective studies link PCI with neurotoxicity, however, the available prospective randomized studies do not support this view. But what kind of side effects do we actually expect?

Acute toxicity of cranial radiotherapy includes headaches, mood disturbances, nausea, vomiting, alopecia, serous otitis, and skin erythema. These problems are reversible after days to weeks, mostly without medication. A transient increase of peritumoral edema which is the pathophysiological cause for acute radiation brain damage is not expected in these patients because of the lack of macroscopic brain metastases. Healthy brain tissue does not react with edema after single doses between 2-3 Gy per fraction, doses $>6$ Gy are necessary to induce these complications.

Late radiation induced neurotoxicity may extend from mild neuropsychological deficits to overt cerebral necrosis. The incidence is in general less than $10 \%$ with a latent period of several years, depending on tumor type, observation time and biological total dose and radiation volume [9]. One side effect is encephalopathy resulting in reduced intelligence and cognition. There are several studies about PCI and cognitive impairment in adults, but only few with sufficient statistical power and planned prospectively.

\begin{tabular}{ll}
\hline KARGER & ( 2002 S. Karger GmbH, Freiburg \\
$\begin{array}{l}\text { Fax +497614520714 } \\
\begin{array}{l}\text { E-mail Information@Karger.de } \\
\text { www.karger.com }\end{array}\end{array}$ & Accessible online at: \\
www.karger.com/journals/onk
\end{tabular}

Prof. Dr. Frederik Wenz Institut für Klinische Radiologie Sektion Strahlentherapie

Universitätsklinikum Mannheim Theodor-Kutzer-Ufer 1-3 D-68167 Mannheim (Germany) 
There have been 3 prospective, randomized controlled trials that have examined cognitive functioning after PCI [1, 3, 4]. In the study by Arriagada et al. [3] about 300 patients with SCLC in complete remssion were randomized to PCI $(8 \times 3 \mathrm{~Gy})$ or observation. A neuropsychological examination and a computer tomography (CT) were performed at the time of random assignment and repeatedly assessed up to 48 months. There were no significant differences between the two groups in terms of neuropsychological function or CT abnormalities. The second prospective study from Gregor et al. [4] examined cognitive functions as well as quality of life. 136 patients were included in the evaluation that comprised auditory mental tracking, perceptual organization, visual memory, memory span, and verbal learning. The tests were administered at the time of randomization, after 6 and 12 months, together with an assessment of depression and quality of life. In both groups, there was impairment of cognitive function and quality of life before PCI and additional impairment at 6 months and 1 year, but no consistent difference between the two groups and thus no evidence of major impairment attributable to PCI given with doses of $1 \times 8$ Gy to $8 \times 3 \mathrm{~Gy}$.

The third study, from Komaki et al. [1], came to the conclusion that a high proportion of neurologically normal appearing patients with limited disease SCLC and favorable response to combination chemotherapy have specific cognitive deficits before receiving PCI. Short-term (6-20 months) observations after PCI have shown no significant deterioration.

Taken together, the findings of these studies suggest that any possible neurotoxicity associated with PCI is not clinically significant within a period of a few years. It should be noted that other factors than radiation toxicity can also contribute to neurological complications e.g. anticancer drugs, old age, alcohol, micrometastases, and paraneoplastic encephalomyelitis. Long-term side effects of PCI like ataxia, dementia, and seizures that have been published in several studies mainly resulted from reports with limited patient numbers when radiotherapy was given in large fractions $\geq 3$ Gy [7], with high total doses, and in combination with nitrosoureas as chemotherapy.

\section{When to Apply PCI in SCLC?}

There is still insufficient evidence to give a definitive recommendation concerning the optimal timing of PCI in relation to chemotherapy. All of the above-described trials involved patients who received PCI after completion of induction chemotherapy or chemoradiotherapy. There have been two studies giving PCI before chemotherapy [10, 11]. However, the optimal application time of brain irradiation in relation to administration of chemotherapy was not systematically evaluated. CCOPGI's Lung Cancer Disease Site Group members generally felt that it should be given as soon as possible after completion of chemotherapy but not concurrent with it because of potential interaction of drug and radiation, which
Table 1. The effects on tumor cell kill and healthy brain tissue of different fractionation schemes can be compared using the linear-quadratic model (equation 1): and the BED (biologically equivalent dose) formalism (equation 2).

Equation 1: survival fraction $(\mathrm{SF})=\alpha \mathrm{D}+\mathrm{bD}^{2}$

Equation 2: BED $[\mathrm{Gy}]=\mathrm{nd}[1+\mathrm{d} /(\alpha / \beta)]$

\begin{tabular}{lllll}
\hline TD, Gy & SD, Gy & $\begin{array}{l}\text { BED tumor, Gy } \\
(\alpha / \beta=10 \text { Gy })\end{array}$ & $\begin{array}{l}\text { BED CNS, Gy } \\
(\alpha / \beta=3 \mathrm{~Gy})\end{array}$ & $\begin{array}{l}\text { Therapeutic } \\
\text { index }\end{array}$ \\
\hline 30 & 3 & 39.9 & 60 & 1.54 \\
30 & 2 & 36.0 & 50 & 1.39 \\
36 & 2 & 43.2 & 60 & 1.38 \\
\hline
\end{tabular}

$\mathrm{TD}=$ total dose $\mathrm{SD}=$ single dose

might increase the risk of late neurotoxicity [2, 6, 12]. There is evidence that the risk for neurotoxicity is highest when chemotherapy is given simultaneously, especially with large fraction sizes [4].

\section{How Much PCI Should Be Given?}

The answer to the question of total dose and dose per fraction is important to achieve an optimal balance between effectivity and toxicity, i.e. therapeutic index. It is obvious that there is a dose effect for effectivity i.e. reduction of frequency of metastases and also for toxicity, with higher doses being more effective but also more toxic. There have been various studies with different total doses and doses per fraction and there is considerable knowledge about the underlying biologic effects to make reasonable suggestions as to dose and total dose.

Regarding tumor cell kill, one may argue based on the available data that doses below 24-25 Gy in conventional fractionation are less effective than doses at 30-40 Gy. Gregor et al. [4] reported an initial 3-armed randomized trial of 'no PCI' vs. 'PCI 24' (24 Gy in 2 Gy fractions) vs. 'PCI 36' (36 Gy in 2 Gy fractions). They suggested that the higher dose was more effective than the lower one. There was a significant difference between 'PCI 36' and 'no PCI' (hazard ratio, 0.16; 95\% confidence interval, 0.07-0.36; $\mathrm{p}=0.0007$ ) and little if any difference between 'PCI 24' and 'no PCI' (hazard ratio, 0.71; 95\% confidence interval, 0.36-1.43; $\mathrm{p}=$ not reported).

The meta-analysis from Auperin et al. [8] included studies that examined PCI doses ranging from 8 to $40 \mathrm{~Gy}$, given in 1-20 fractions. When trials were categorized into 4 dose groups ( 8 Gy, 24/25 Gy, 30 Gy, 36-40 Gy), there was again a significant trend towards an increased effectivity of PCI with increasing total dose $(p=0.02)$.

As to toxicity, it is important to keep in mind that the central nervous system is a 'late-reacting' organ with a low $\alpha / \beta$ coefficient. As a consequence, late damage to brain tissue is not only dependent on the total dose (and volume of irradiation), 
but also crucially dependent on the single dose given per day. This fact should be briefly illustrated using the following table and equation based on the linear quadratic model. The effect of radiation on cell kill - tumor and normal cell kill - can be described using equation 1, where the survival fraction (SF) is put into relation with the radiation dose multiplied by two tissue-specific parameters $\alpha$ and $\beta$, which are derived from the shape of the respective survival curves. Because of effects like recovery from sublethal radiation damage between two radiation doses, the biologically equivalent dose (BED) is given by equation 2 taking the fractionation ( $\mathrm{n}=$ number of fractions, $\mathrm{d}$ = single dose per day) into account. Using the BED, one can compare the effects different fractionation schemes will induce on the respective tissue characterized by the parameter $\alpha / \beta$. Table 1 compares the effects of typical radiation doses on tumor cells and normal brain tissue. One can see that $30 \mathrm{~Gy}$ given in 10 fractions has the same toxicity (biologic CNS dose) as compared to 36 Gy in 18 fractions, but less tumor cell kill (lower biologic tumor dose), resulting in a worse therapeutic index. Because brain tissue has a comparably low $\alpha / \beta$ value, it is relatively sensitive to changes of the fraction size, which is the explanation for the differences in therapeutic index.

\section{Conclusion}

In conclusion, we recommend to use prophylactic cranial irradiation in patients with limited-disease SCLC and a significant response to systemic therapy in addition to thoracic radiotherapy, because of the survival benefit achieved with a low risk of chronic side effects. PCI should be given early after induction of chemotherapy, not concurrently. A total dose of 30-36 Gy should be given in doses of 2 Gy to achieve the best therapeutic index.

\section{References}

1 Komaki R, Meyers CA, Shin DM, Garden AS, Byrne K, Nickens JA, Cox JD: Evaluation of cognitive function in patients with limited small cell lung cancer prior to and shortly following prophylactic cranial irradiation. Int J Radiat Oncol Biol Phys 1995;33:179-182.

2 Healey EA, Abner A: Thoracic and cranial radiotherapy for limited-stage small cell lung cancer. Chest 1995;107:249-254.

3 Arriagada R, LeChevalier T, Borie F, Riviere A, Chomy P, Monnet I, Tardivon A, Viader F, Tarayre M, Benhamou S: Prophylactic cranial irradiation for patients with small-cell lung cancer in complete remission. J Natl Cancer Inst 1995;87:183-190.

4 Gregor ACA, Stephens RJ, Kirkpatrick JA, Yarnold JR, Girling DJ, Macbeth FR, Stout R, Machin D: Prophylactic cranial irradiation is indicated following complete response to induction therapy in small cell lung cancer: Results of a multicentre randomised trial. Eur J Cancer 1997;33: 1752-1758.
5 Ball LMP: Prophylactic Cranial Irradiation: More questions than answers. Sem Radiat Oncol 1995;5: 61-68.

6 Fleck JF, Einhorn LH, Lauer RC, Schultz SM, Miller ME: Is prophylactic cranial irradiation indicated in small-cell lung cancer? J Clin Oncol 1990; 8: 209-214.

7 Shaw EG, Su JQ, Eagan RT, Jett JR, Maksymiuk AW, Deigert FA: Prophylactic cranial irradiation in complete responders with small-cell lung cancer: Analysis of the Mayo Clinic and North Central Cancer Treatment Group data bases. J Clin Oncol 1994;12:2327-2332

8 Auperin A, Arriagada R, Pignon JP, Le Pechoux C, Gregor A, Stephens RJ, Kristjansen PEG, Johnson BE, Ueoka H, Wagner H, Aisner J: Prophylactic cranial irradiation for patients with small-cell lung cancer in complete remission. N Engl J Med 1999; 341:476-484.
9 Wenz F, Guttenberger R, Engenhart R: Gehirn, Rückenmark und Sinnesorgane; in Doerr W, Zimmermann J, Seegenschmiedt MH (Hrsg): Klinisches Kompendium Normalgewebsreaktionen. München, Urban \& Vogel, 2000, pp 178-190.

10 Hugli A, Moro D, Mermillod B, Bolla M, Alberto P, Bonnefoi H, Mirabell R: Phase II trial of upfront accelerated thoracic radiotherapy combined with chemotherapy and optional up-front prophylactic cranial irradiation in limited small-cell lung cancer. Groupe d'Oncologie Thoracique des Régions Alpines. J Clin Oncol 2000;18:1662-1667.

11 Work E, Nielson OS, Bentzen SM, Fode K, Palshof T: Randomized study of initial versus late chest irradiation combined with chemotherapy in limitedstage small-cell lung cancer. Aarhus Lung Cancer Group 1997;15:3030-3037.

12 Kotalik J, Yu E, Markman BR, Evans WK, Cancer Care Ontario Practice Guidelines Initiative Lung Cancer Disease Site Group: Practice guideline on prophylactic cranial irradiation in small-cell lung cancer. Int J Radiat Oncol Biol Phys 2001;50:309316. 